Health Program, Istanbul; and University of Ankara Medical School, Ankara, Turkey. The prefrontal cortex rCBF during resting conditions showed increased lateralization from right to left with age in ADHD subjects, and compared to controls, ADHD was associated with lower right prefrontal/frontal and higher parietal $\mathrm{rCBF}$. These differences were greater in subjects older than 7 years. The left hemisphere dominance in the prefrontal cortex increased significantly with age in ADHD subjects, whereas the control group showed no significant correlations between age and asymmetry of rCBF. (Oner O, Oner P, Aysev A, Kucuk O, Ibis E. Regional cerebral blood flow in children with ADHD: changes with age. Brain Dev June 2005;27:279-285). (Respond: O. Oner, Gazi Ethem Pasa Sokak, Atala Apt 6/1, Senesenevler, 34742 Istanbul, Turkey).

COMMENT. The lower right prefrontal and frontal cerebral blood flow in ADHD subjects correlates with previous reports of an abnormal right frontal development on functional imaging studies (Castellanos FX et al. 1996; Ped Neur Briefs Aug 1996). Decreased volume of prefrontal cortex, caudate nucleus, and globus pallidus on the right side point to a dysfunction of the prefrontal-striatal circuits in ADHD.

\title{
AGGRESSIVE BITING BEHAVIOR AND SEIZURES
}

The biting behavior (BB) and other aggressive gestures in a group of 11 patients ( 8 male; 3 female) with drug-resistant seizures were studied in presurgical evaluations using video-EEG/SEEG monitoring at University of Bologna; Niguarda Hospital, Milan; and University of Modena, Italy. Seizure onset was at age 1 to 21 , and age at evaluation was 3059 years. BB was reflexive, occurring during or after a seizure, and evoked by intrusion of the examiner's hand near the patient's face. The act was associated with emotional arousal, fear, or anger, and was accompanied by aggressive gestures. The EEG showed that BB was localized to ictal involvement of the amygdala/hippocampal and the orbitomedial prefrontal regions. (Tassinari CA, Tassi L, Calandra-Buonaura $\mathrm{G}$ et al. Biting behavior, aggression, and seizures. Epilepsia May 2005;46:654-663). (Reprints: Dr S Meletti, Division of Neurology, Bellaria Hospital, University of Bologna, Via Altura 3, Bologna 40139, Italy).

COMMENT. This study concerned adults whose seizures began in childhood. The authors emphasize that violence is exceptional during epileptic seizures, and distinct from that reported with postictal psychosis. The diagnosis requires EEG confirmation during BB. In children with ADHD and comorbid oppositional defiance disorder, biting and aggressive tendencies are not uncommon, and abnormal EEGs have been reported with ADHD in 15\% of cases (Hemmer SA, Pasternak JK et al, 2001; Ped Neur Briefs May 2003). A video-EEG is necessary to relate $\mathrm{BB}$ to ictal activity, as a prelude to a trial of antiepileptic medication. Several studies have linked behavioral abnormalities to epilepsy in childhood, but the indications for antiepileptic treatment are controversial (Boone KB et al, 1988; [Ped Neur Briefs April 1988]; Austin JK et al, 1992; [Ped Neur Briefs Jan 1993]; Wakai S et al, 1994 [Ped Neur Briefs Nov 1994]; Amir N et al, 1994 [Ped Neur Briefs Dec 1994]). 